\title{
$\mathrm{BIM}$ 기반 건축설계 관리 지원을 위한 클라우드 컴퓨팅 서비스 기능 제안
}

\section{A Proposal of Features of Cloud Computing Service for BIM based Architectural Design Management}

\author{
안민규 ${ }^{1)}$, 최종문 ${ }^{2)}$, 이재욱 ${ }^{3)}$, 윤수원 ${ }^{4)}$ \\ An, Min-Gyu' ${ }^{1)} \cdot$ Choi, Jong-Moon $^{2)} \cdot$ Lee, Jaewook ${ }^{3)} \cdot$ Yoon, Su-Won ${ }^{4)}$ \\ Received May 8, 2014 / Accepted May 15, 2014
}

\begin{abstract}
Recently, there have been various attempts for the adoption and spread of Building Information Modeling (BIM) in the construction industry. However, the spread of BIM has been less satisfied than expected, because of the insufficient, expensive hardware and software for the authoring, analysis and so forth. As a solution to resolve the obstacles, the applications of cloud computing technology to BIM have been introduced. Due to the vendor-dependent functions and lack of verification on the work process, the spread of cloud-based BIM has been limited in Korea. Therefore, this study proposes the functions of cloud computing services which can support BIM-based design processes through the review of practitioners, questionnaire survey and analysis of design process.
\end{abstract}

KEYWORDS: Cloud Computing Service, BIM based Design Collaboration, Design Management

키워드: 클라우드 컴퓨팅 서비스, BIM 기반 협업 설계, 설계 관리

\section{1. 서론}

\section{1 연구의 배경 및 목적}

건설 산업에서 $\mathrm{BIM}$ 적용이 확대되면서, 과거 $2 \mathrm{D}$ 기반의 설계 후 3D 전환설계를 수행하거나 2D와 BIM을 병행하는 업무 방식 에서, 설계 초기부터 BIM을 전체 프로젝트에서 활용하는 방식으 로 업무 프로세스가 변화되고 있다(Hannele et al. 2012).

하지만 현재 국내 건설 산업에서 활용되고 있는 BIM 기술은 주로 저작 또는 해석 위주의 기능을 가진 개인별 상용 BIM 소프 트웨어를 활용한 정보 생성 및 파일 단위의 정보 교환을 통해 업무를 진행함으로써 프로젝트 생애주기 동안 발생되는 BIM 정 보를 효과적으로 생성 · 통합 · 공유 · 활용하는데 한계를 가지 고 있다. 또한 프로젝트에 참여하는 다양한 주체간의 업무 프로 세스를 지원하기 위해서는 고가의 소프트웨어 및 하드웨어를
구매해야하는 부담 때문에, 소규모의 기업 또는 프로젝트에서의 $\mathrm{BIM}$ 활용은 개인 단위별 정보 생성 및 정보 전달의 형태로 제약 받고 있다. 즉, 현재 BIM 기술은 업무 프로세스의 미정착화(Seo et al. 2010), 업무 프로세스를 지원하기 위한 서비스 부족, 그리 고 업무 프로세스 운영을 위해 필수적으로 필요한 고가의 소프 트웨어와 하드웨어의 미비로 인해, 협업설계에서의 정보교환의 어려움 등을 효과적으로 해결하기 위해 도입된 BIM 기술(Kalay 2004)을 효과적으로 활용 - 확산하지 못하고 있는 상태이다.

한편, 해외에서는 이러한 문제 해결을 위해, 클라우드 컴퓨팅 기술을 BIM과 접목하여 보다 경제적이고 효과적으로 BIM 저작 결과물을 공유·관리하는 시스템(BIM 9, SkyBIM, BIM 360 Glue, BIM Cloud 등)이 등장하고 있으나, 특정 소프트웨어 중심 의 기능 제공 및 국내 업무 프로세스에 대한 검증 미흡으로 확산 이 미비한 상태이다.

※ 이 논문은 ‘한국BIM학회 2014년도 정기학술대회'에서 발표된 내용을 근거로 하여 학술지 논문으로 재구성하였음.

${ }^{1)}$ 학생회원, 세종대학교 건축공학과 석사과정 (amg0602@naver.com)

${ }^{2)}$ 정회원, 포스코건설 기술연구소, 공학석사 (colormoon@poscoenc.com)

${ }^{3)}$ 정회원, 세종대학교 건축공학과 교수, 공학박사 (jaewook@sejong.ac.kr)

${ }^{4)}$ 정회원, 포스코건설 기술연구소, 공학박사 (yoonsuwon@poscoenc.com) (교신저자) 
따라서 본 연구에서는 상용 BIM 클라우드 서비스의 기능고찰 과 실무자를 대상으로 한 설문조사, BIM 기반 설계프로세스 분 석을 통해 전반적인 $\mathrm{BIM}$ 기반의 건축설계 관리를 지원할 수 있 는 클라우드 컴퓨팅 서비스의 주요 기능을 제안하고자 한다.

\section{2 연구의 범위 및 방법}

본 연구는 $\mathrm{BIM}$ 이 다루는 건물의 생애주기 중에서, BIM 정보 가 생성되고, 다양한 주체들에 의해 BIM 정보의 교환 및 변화가 빈번히 일어나는 설계 단계(기획설계, 계획설계, 기본설계, 실시 설계)를 대상으로, BIM 정보의 생성 - 통합 · 공유 - 활용을 지원 할 수 있는 클라우드 서비스의 기능을 제안하였다. 이를 위해 본 연구에서는 아래 Figure 1과 같은 순서로 연구를 진행하였다.

첫째, 해외에서 개발 - 제안된 BIM 360 Glue, SkyBIM, Graphisoft BIMcloud, BIM 9, G Team, Tekla BIMSight 등과 같은 대표적인 상용 BIM 클라우드 서비스를 대상으로 제공 서비스 및 기능을 분석하였다. 이를 통해 기존의 BIM 클라우드 서비스 기능과 서 비스 방식, 연동 소프트웨어를 파악하였으며, 조사된 사항은 본 연구에서 제안한 클라우드 컴퓨팅 기반 BIM 서비스 기능의 기초 자료로 활용하였다.

둘째, 상용 BIM 클라우드 서비스에서 도출한 주요 기능 을 토대로 요구사항 조사를 위한 설문지를 작성한 다음, 설계업무 실무자를 대상으로 설문조사를 실시하였다.

셋째, 설문조사를 통해 수집한 데이터를 정리하고 분석하였 으며, 이를 통해 BIM 클라우드 서비스 기능개발 방향을 설정하 였다.

넷째, 클라우드 컴퓨팅을 접목한 BIM 서비스가 지원할 수 있 는 설계 프로세스와 전문가 인터뷰를 통해 접목을 고려할 수 있는 업무 단계 도출을 위해 설계 프로세스를 분석하였다.

다섯째, 실무자 수요조사 및 전문가의 프로세스 검토 · 분석 의 결과를 바탕으로, $\mathrm{BIM}$ 기반 건축설계 관리 지원을 위한 클라

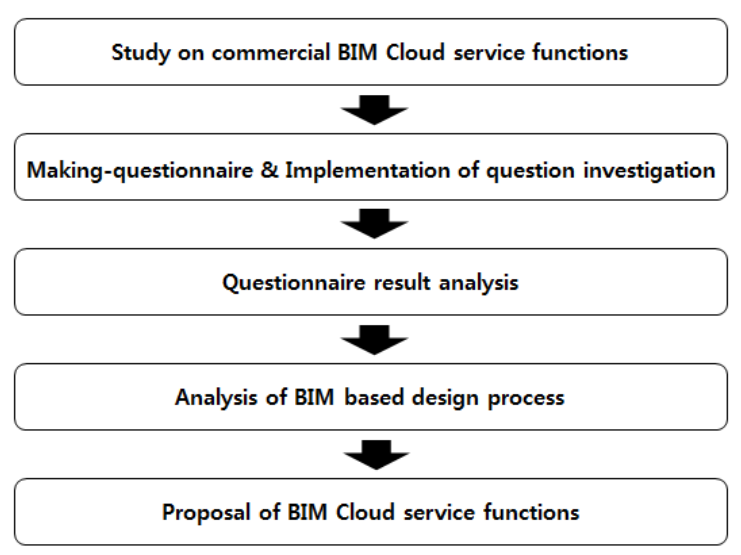

Figure 1 Study Flow
우드 컴퓨팅 서비스의 기능을 제안하였다.

\section{2. 상용 BIM 클라우드 서비스의 주요 기능 교찰}

\section{1 기존 BIM 클라우드 연구에서의 서비스 기능}

클라우드 컴퓨팅 기술이란 네트워크, 서버, 저장소, 어플리케 이션, 서비스와 같이 설정이나 공유가 가능한 컴퓨팅 자원에 대 해 언제 어디서든 편리하게 네트워크 접근이 가능한 기술(Mell and Grance 2009)로 정의되며, BIM 클라우드는 이러한 클라우 드 컴퓨팅 기술을 BIM 기술과 연계하여 다양한 서비스를 구현하 고 제공하는 시스템을 의미한다.

기존의 BIM 클라우드 서비스와 관련된 연구로는 BIM 클라우 드 체제에 대한 연구(Amarnath et al. 2011), 클라우드 기술을 $\mathrm{BIM}$ 시각화와 조작에 적용하기 위한 연구(Chuang et al. 2011), LEED 자동화 업무 지원을 위해 BIM 클라우드 서비스를 도입하 기 위한 연구(Wu and Issa 2012) 등 BIM과 클라우드 컴퓨팅의 접목 방법 또는 특정 업무를 대상으로 서비스 구축 방안에 대한 연구들이 시도되었으나, 건설 프로젝트의 설계 단계 등과 같이, 업무 프로세스 전체를 지원하기 위한 기능 고찰은 미비한 실정 이다.

\section{2 상용 BIM 클라우드 서비스 기능}

$\mathrm{BIM}$ 분야의 클라우드 컴퓨팅 서비스는 2000년대 후반 모바 일 또는 원격지에서 $3 \mathrm{D}$ 뷰어(Viewer)를 기반으로 BIM 모델을 조회 · 검토하는 것으로 시작하여, BIM 기반 프로젝트의 운영 및 관리의 형태로 발전하고 있다(Yoon 2013).

Table 1은 현재 해외에서 상용화된 BIM 클라우드 서비스의 주요 기능을 정리한 것으로, 현재 해외에서 상용화되어 사용되 고 있는 클라우드 서비스는 기업이나 프로젝트 조직 내 Private 클라우드 서비스를 지향하는 가상화 솔루션(VDI 등) 기반의 BIM 클라우드 서비스(BIM 9 등), 다수의 사용자 또는 주체들이 활용 가능한 Public 클라우드 서비스를 지원하는 BIM 기반 프로젝트 협업/관리 서비스(BIM 360 Glue, G Team, Tekla BIMsight 등), 그리고 Sky BIM과 같이 견적과 같은 특정 업무를 지원하는 서비 스 등이 있는 것으로 조사되었다.

그리고 이러한 서비스들은 기존의 웹 기반의 협업 시스템 (PMIS 등)이 텍스트, 파일 위주의 정보 관리에 초점을 맞추고 있는 것과 달리 BIM 모델 뷰어(Viewer)를 중심으로 모델 관리, 협업 지원, 간섭체크 등의 기능을 제공하는 것으로 나타났다. 또한, 서비스 방식은 주로 Public 서비스를 선호하는 것으로 나 타났다. 이를 통해 현재 BIM 클라우드 서비스 사용자들은 개인 적인 업무 지원보다는 프로젝트 참여자 간 협업 지원을 더 선호 한다는 것을 예상할 수 있었다. 
Table 1 Main functions of commercial BIM Cloud service

\begin{tabular}{|c|c|c|c|}
\hline $\begin{array}{c}\text { Product } \\
\text { name }\end{array}$ & $\begin{array}{l}\text { Service } \\
\text { method }\end{array}$ & Main functions & $\begin{array}{l}\text { Linked } \\
\text { S/W }\end{array}$ \\
\hline $\begin{array}{c}\text { BIM } 360 \\
\text { Glue }\end{array}$ & $\begin{array}{l}\text { Public } \\
\text { cloud }\end{array}$ & $\begin{array}{l}\text { - Project/User management } \\
\text { - Model management/viewer } \\
\text { (markup, measurement, etc) } \\
\text { - Collaboration (unit work management, } \\
\text { notice/sharing, attachment, etc) } \\
\text { - Work type for model integration/ } \\
\text { management } \\
\text { - Interference check }\end{array}$ & $\begin{array}{l}\text { Autodesk } \\
\text { AutoCAD, } \\
\text { Revit, } \\
\text { Navisworks }\end{array}$ \\
\hline SkyBIM & $\begin{array}{l}\text { Public } \\
\text { cloud }\end{array}$ & $\begin{array}{l}\text { - Project/User management } \\
\text { - BIM based squaring/estimation } \\
\text { service } \\
\text { - Cloud based BIM life-cycle } \\
\text { information save/management } \\
\text { (Model and relevant data registration } \\
\text { and collaboration support) } \\
\text { - Model viewer, etc }\end{array}$ & $\begin{array}{c}\text { Autodesk } \\
\text { Revit }\end{array}$ \\
\hline BIM 9 & $\begin{array}{l}\text { Private } \\
\text { cloud }\end{array}$ & $\begin{array}{l}\text { - Project/User management } \\
\text { - Offering a virtualization based cloud } \\
\text { service }\end{array}$ & $\begin{array}{c}\text { Autodesk } \\
\text { Revit }\end{array}$ \\
\hline G Team & $\begin{array}{l}\text { Public } \\
\text { cloud }\end{array}$ & $\begin{array}{l}\text { - Project/User management } \\
\text { (Project history management, etc) } \\
\text { - Model management/viewer } \\
\text { (model sync, markup, measurement, } \\
\text { etc) } \\
\text { - Collaboration } \\
\text { (message, comment, file sharing, etc) } \\
\text { - Interference check } \\
\text { - Security management }\end{array}$ & $\begin{array}{l}\text { Revit, } \\
\text { AutoCAD, } \\
\text { Digital } \\
\text { Project, } \\
\text { Rhino, } \\
\text { Sketch up }\end{array}$ \\
\hline $\begin{array}{c}\text { Tekla } \\
\text { BIMSight }\end{array}$ & $\begin{array}{l}\text { Public } \\
\text { cloud }\end{array}$ & $\begin{array}{l}\text { - Real time collaboration support } \\
\text { - Model management/viewer } \\
\text { - Interference/Dispute adjustment } \\
\text { - Work type for model integration/ } \\
\text { management } \\
\text { - Issue sharing/communication }\end{array}$ & $\begin{array}{c}\text { Tekla, } \\
\text { Sketch up }\end{array}$ \\
\hline $\begin{array}{l}\text { Graphisoft } \\
\text { BIMcloud }\end{array}$ & $\begin{array}{l}\text { Public } \\
\text { cloud }\end{array}$ & $\begin{array}{l}\text { - BIM model server based collaboration } \\
\text { design support } \\
\text { - Many BIM model server management } \\
\text { support } \\
\text { - Viewer }\end{array}$ & ArchiCAD \\
\hline
\end{tabular}

\section{BIM 클라우드 서비스의 요구사항 조사}

\section{1 설문조사 개요}

본 연구에서는 실무자들의 BIM 클라우드 서비스에 대한 전반 적인 요구사항을 알아보기 위해 앞선 상용 BIM 클라우드 서비스 의 주요 기능분석을 토대로 Figure 2와 같은 설문지를 작성하였다.

설문지는 1) 클라우드 컴퓨팅의 도입 필요성을 확인하기 위한 $\mathrm{BIM}$ 업무 수행 환경조사, 2) 클라우드 컴퓨팅 기반 BIM 서비스에 대한 요구사항 및 선호도를 조하기 위한 필요 기능 조사, 3) 클라 우드 기반 BIM 서비스 의 운영 방안, 그리고 4) 클라우드 기반 $\mathrm{BIM}$ 서비스 제도/정책 지원방안으로 구성되었다. 그리고 설문 조사는 건축사 협회 교육생 100 명을 대상으로 실시하였다.

설문에 대한 분석은 설문 대상 중 $\mathrm{BIM}$ 수행 경험 부재 등의 이유로 응답을 거부하거나 부분 응답으로 설문 결과에 반영하기 힘든 데이터를 제외한 33 개를 대상으로 실시하였으며, 분석 대

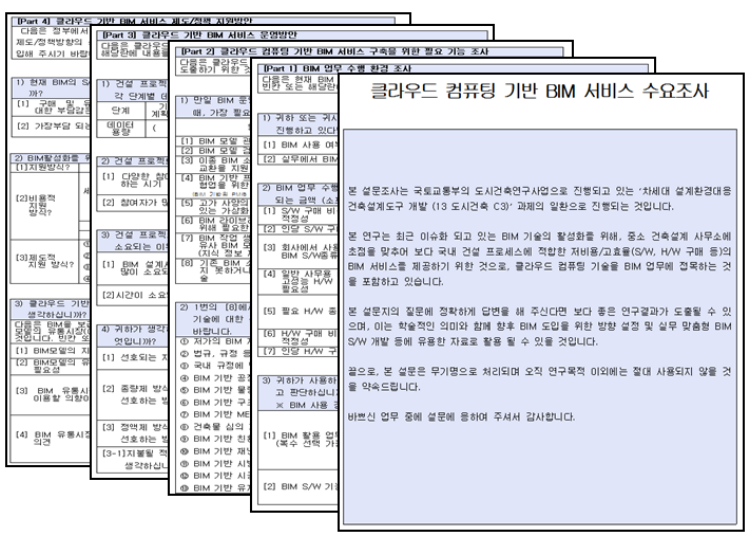

Figure 2 Questionnaire forms

상 설문 응답자의 설계 경력은 평균 7.9년이고, 응답자의 수행업 무는 건축 설계 30 명, 감리 병행 3 명이었다.

\section{2 현행 BIM 수행 환경 분석}

현행 $\mathrm{BIM}$ 수행 환경 분석은 현재 활용하고 있는 $\mathrm{BIM}$ 소프트 웨어, BIM 소프트웨어 실행에 필요한 하드웨어, 그리고 BIM 소 프트웨어가 제공하는 기능에 대한 만족도를 조사하기 위한 것으 로, 조사 결과는 Figure 3 과 같이 나타났다.

먼저, BIM 관련 소프트웨어 구축비용의 적절성에 대해서는 설문자의 $90 \%$ 가 고가라고 응답하였다. 또한, BIM 관련 하드웨 어 구축비용의 적절성에 대해서도 상당수가 고가라는 의견을 가지고 있었다. 이는 현재 BIM 업무를 수행함에 있어 비용이 많이 들어감을 의미하며, 이러한 문제점을 개선하기 위해 현재 상용화된 BIM 소프트웨어, 하드웨어 보다 저렴한 서비스로 제공 해야 할 것이다. 이를 통해 BIM 관련 업무 수행을 위한 비용측면 의 개선이 이루어질 것이라고 판단된다.

다음으로 현재 BIM 소프트웨어 적용 분야는 모델링/ 도면화 부분이 $30.4 \%$ 로 가장 높게 나타났다. 이러한 결과를 통해 아직 $\mathrm{BIM}$ 소프트웨어는 주로 모델링과 도면화를 위해 사용되고 있다 는 것을 알 수 있었으며, 다른 분야도 어느 정도 사용하고 있지만 모델링/도면화 분야와는 적지 않은 차이가 있었다. 따라서 BIM 소프트웨어를 광범위하게 사용하기 위해서는 분야별 BIM 소프 트웨어의 기능 다양화가 필요하다.

끝으로 BIM 소프트웨어의 개선 방향에 대한 질문에는 타공종 과의 연계성 향상과 라이브러의 개선에 대한 의견이 가장 많았 다. 또한, 각 항목에 대한 응답비율이 $50 \%$ 이상인 것으로 보아 기존 BIM 소프트웨어의 전반적인 개선이 필요하다는 것을 알 수 있었다.

설문조사 결과, 현재 BIM 소프트웨어를 활용한 업무 수행 환 경에 BIM 소프트웨어 및 하드웨어의 비용, 적용 분야 등의 문제 들이 존재하며, 이러한 문제들을 개선할 수 있는 BIM 클라우드 


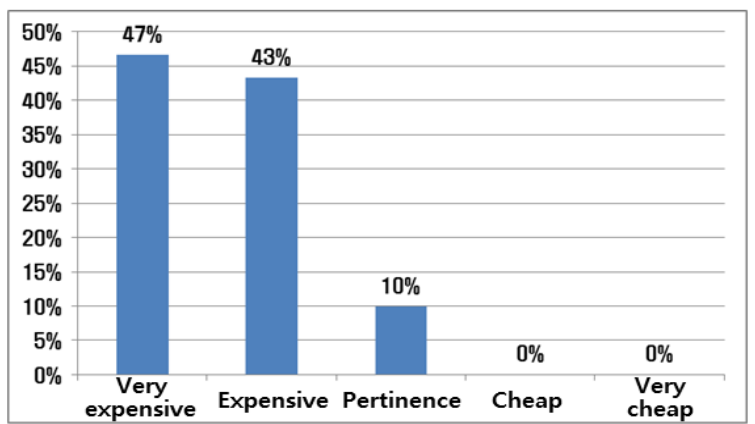

[Appropriacy of BIM S/W cost]

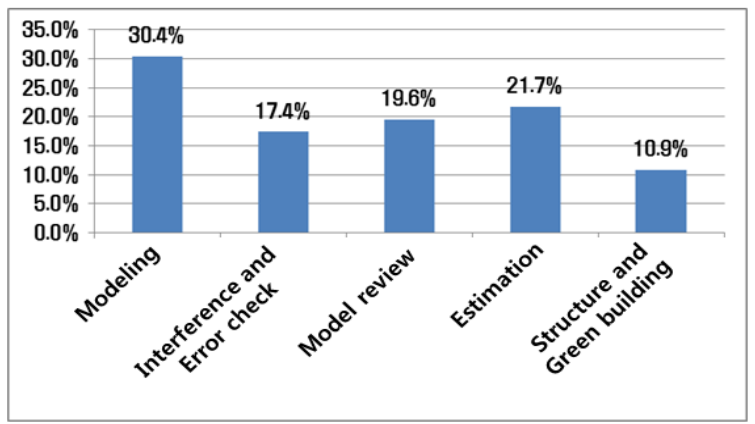

[Applying field of BIM S/W]

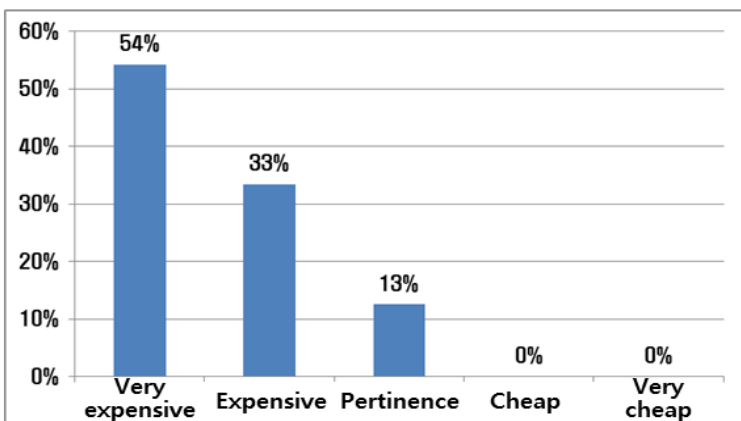

[Appropriacy of BIM H/W cost]

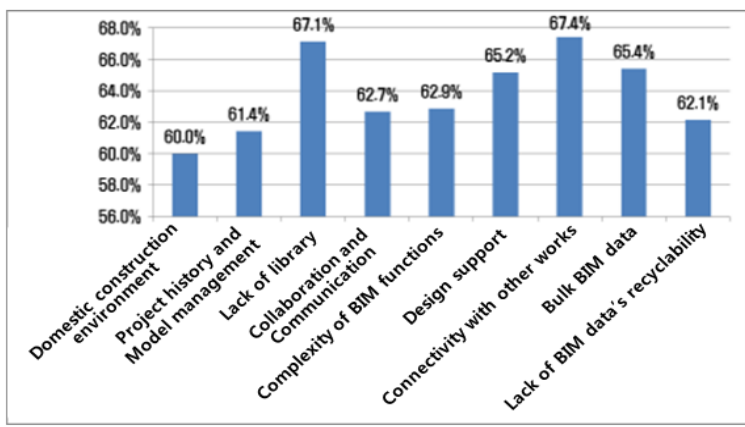

[Improvement direction of BIMS/W]

Figure 3 Questionnaire result for the current BIM performance

서비스가 필요한 것으로 판단한다.

\subsection{BIM 클라우드 서비스 기능 수요}

$\mathrm{BIM}$ 클라우드 서비스의 기능 수요를 파악하기 위하여 상용 서비스에 대한 분석과 전문가 검토를 통해 도출한 기능을 중심 으로 선호도 조사를 실시하였으며, 조사 결과는 Figure 4와 같다.

먼저 BIM 클라우드 서비스 요소 기술에 대한 선호도는 협업 시스템 기술이 $79.2 \%$ 로 가장 높게 나타났으며, 이러한 조사 결 과는 현재 설계협업과정에서 커뮤니케이션의 중요성을 보여주 며(Won et al. 2008), 클라우드 컴퓨팅 기술의 뛰어난 접근성과 데이터 공유 능력을 바탕으로 한 협업지원 기능의 필요성이 높 다는 것을 알 수 있다.

다음으로 추가 어플리케이션 분야에 대한 설문결과에서 $\mathrm{BIM}$ 클라우드 서비스의 필요 어플리케이션 분야 중 응답률 $5 \%$ 이상 인 분야로는 저비용, 법규·규정 등의 룰(Rule) 자동 체크, 국내 규정에 맞는 산출물 추출, 물량 산출 및 견적, 구조, 건축물 심의, 친환경 시뮬레이션 등으로 나타났다.

이러한 설문조사 결과를 통해 본 연구에서 제안하는 추가 $\mathrm{BIM}$ 클라우드 서비스 기능들의 우선순위를 정하였다.

\section{BIM 기반 설계 프로세스 분석}

$\mathrm{BIM}$ 기반 설계 프로세스 분석은 앞서 설문 조사를 통해 분석

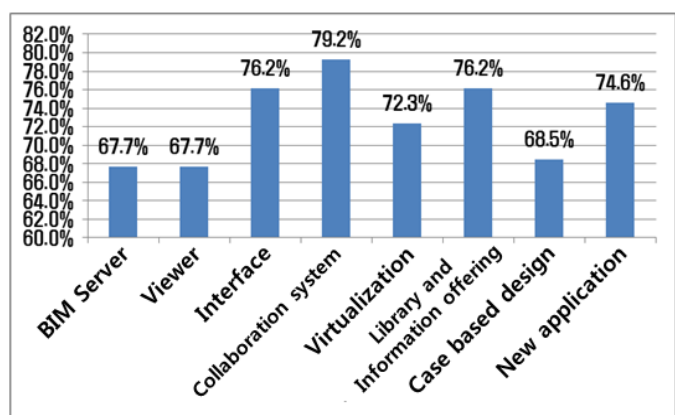

[Preference for the element technology of BIM Cloud service]

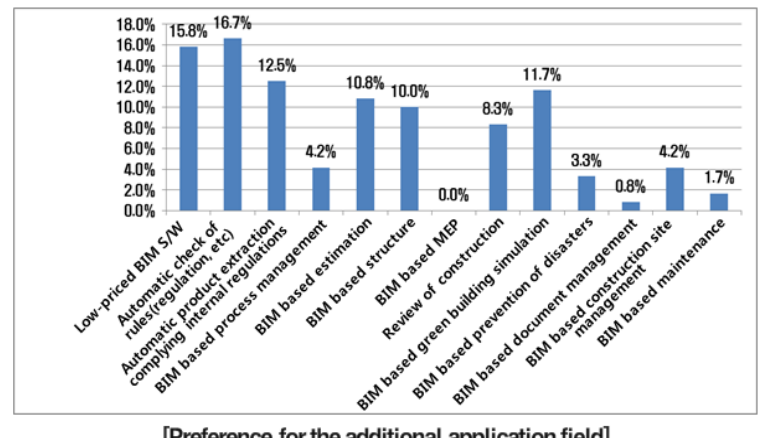

[Preference for the additional application field]

Figure 4 Questionnaire result for requirements of BIM Cloud service

한 BIM 클라우드 서비스 기능이 어떤 단계에서 적용 가능한가를 판단하고, 추가적으로 고려해야할 단계 및 이를 지원하기 위한 기능들을 도출하기 위하여 수행하였다. 설계 프로세스 분석은 


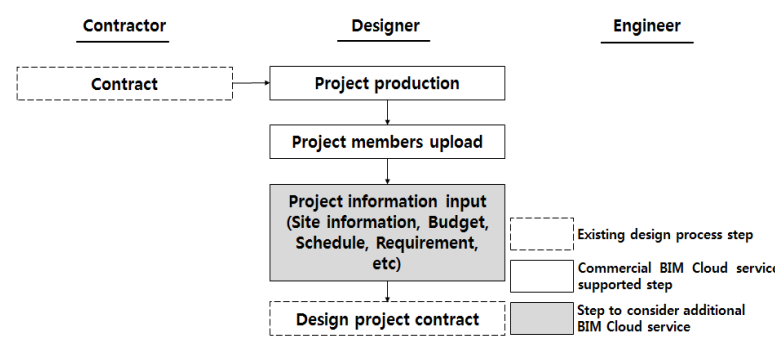

Figure 5 Proposal of BIM Cloud service in the pre-design

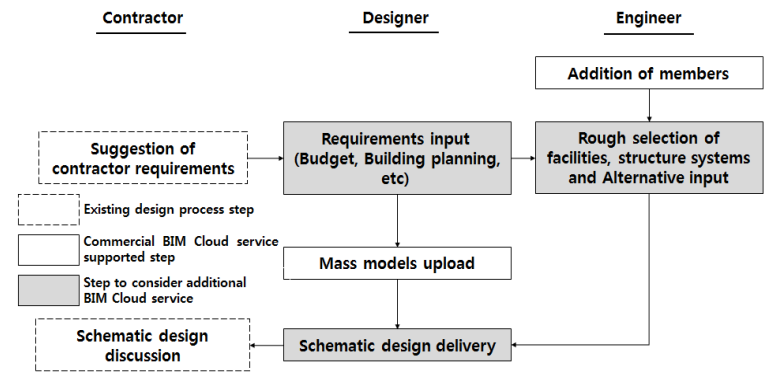

Figure 6 Proposal of BIM Cloud service in the schematic design

먼저, 설계 업무 프로세스 모델을 작성한 다음, 각 설계 단계별 로 BIM 클라우드 서비스 기능의 적용 가능 여부 검토, 그리고 추가적으로 고려해야할 단계 도출 및 추가 기능 검토의 순서로 진행하였다.

먼저, 프로세스 모델은 건축사 협회 등에서 정의한 일반적인 설계 프로세스(KIRA)와 주요 설계 사무소의 설계 프로세스(Lee et al. 2007)를 참조 · 분석하여 단계별로 도식화하였다. 그리고 $\mathrm{BIM}$ 클라우드 서비스를 제공하기 위한 구체적인 단계와 대상을 파악하기 위하여 설계 프로세스를 기획설계, 계획설계, 기본설 계, 실시설계로 구분하였으며, 프로세스 운영 주체를 발주자, 설 계자, 엔지니어로 구분하였다. 다음으로 설계 프로세스에서 서 비스 적용 단계의 세분화를 위하여, Table 1에 정리된 해외 상용 $\mathrm{BIM}$ 클라우드 서비스의 주요 기능, 설문 조사 결과, 전문가 인터 뷰 등을 통하여 단계별 검토를 실시하였다. 그림들에서 점선 박 스는 기존 설계 단계, 실선 박스는 현재 상용 BIM 클라우드 서비 스가 지원하는 설계 단계, 회색 박스는 검토를 통해서 추가로 $\mathrm{BIM}$ 클라우드 서비스 지원을 고려한 단계를 나타낸다.

기존 기획설계 프로세스는 프로젝트 관리, 일정 및 예산 산정, 대지분석 및 시설물 조사, 공간계획, 프로그램 검토, 설계 프로 젝트 계약 등의 업무 단계로 구성되어 있다. 이에 상용 BIM 클라 우드 서비스와 본 연구에서 제안하는 서비스를 적용해 새롭게 제안한 기획설계 프로세스는 Figure 5 와 같다.

기존 기획설계 프로세스에서 상용 BIM 클라우드 서비스는 프로젝트 생성, 프로젝트 멤버 업로드와 같은 기능을 지원하고 있지만, 프로젝트 정보관리를 위한 기능은 지원하지 않는다. 이

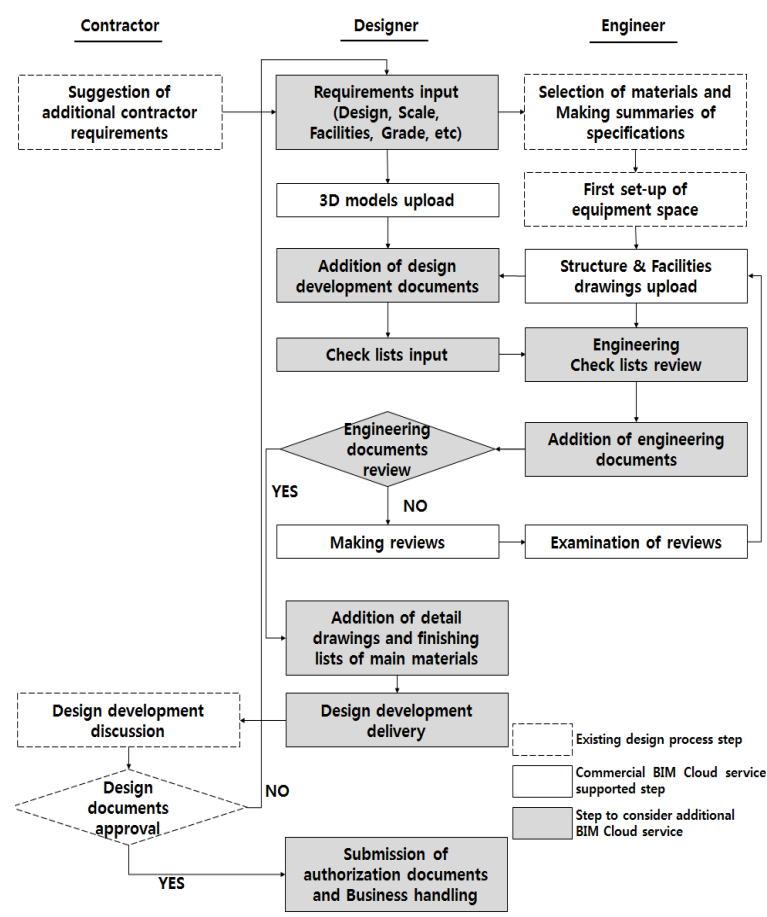

Figure 7 Proposal of BIM Cloud service in the design development

에 대지정보, 예산, 일정, 요구사항 등 프로젝트 정보를 입력할 수 있는 설계 단계를 추가하여 설계 초반부터 설계 정보의 관리 가 가능하도록 하였다.

기존 계획설계 프로세스는 요구사항 검토 및 관리, 예산검토, 대지 및 건물 계획, 매스 모델 제작, 건물 설비 선정 등의 단계로 구성되어 있다. 이러한 기존 프로세스에 BIM 클라우드 서비스를 적용하여 계획설계 프로세스를 제안하였다(Figure 6). 기존 상 용 BIM 클라우드 서비스가 지원할 수 있는 기능은 멤버 추가와 매스 모델 업로드 정도였으나 본 연구에서 제안하는 프로세스에 서는 계획설계에서 발생하는 요구사항과 건물설비 관련 BIM 정 보를 BIM 클라우드에서 관리할 수 있도록 하여 정보활용과 관리 의 용이성을 높이고자 하였다.

기존 기본설계 프로세스는 $3 \mathrm{D}$ 모델 스케치, 기본설계도서 작 성, 체크리스트 작성, 기본 상세도 및 주요 재료 마감표 작성, 인허가 도서 제출 및 업무처리, 재료선정, 구조·설비 도면 작성, 엔지니어링 체크리스트 검토, 리뷰 등의 단계로 구성되어 있다. 이에 BIM 클라우드 서비스를 적용하여 기본설계 프로세스를 새 로 구성하였다(Figure 7). 그림에서 볼 수 있듯이 현재 상용 BIM 클라우드 서비스는 기본설계 프로세스에 대한 지원이 상당히 부족하였다. 이에 본 연구에서는 기존 프로세스를 보완한 기본 설계 프로세스를 제안하였다. 여기에서 가장 중요한 부분은 엔 지니어 도서검토 단계와 인허가 도서 제출 및 업무처리 단계이 다. 엔지니어 도서검토에 대한 BIM 클라우드 서비스 지원은 단 


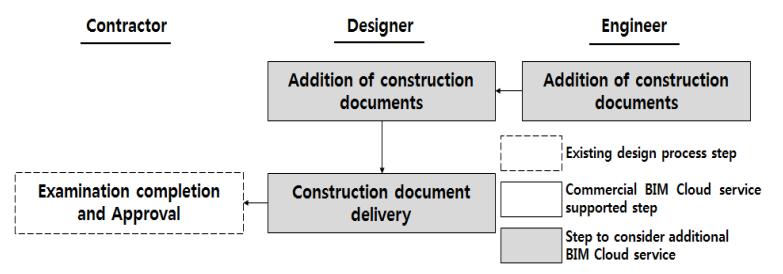

Figure 8 Proposal of BIM Cloud service in the construction document

순 리뷰 검토인 뷰어, 모델체커(간섭), 마크업 등과 더불어 구조 적 결함 검토나 설비용량 - 위치의 적절성을 판별하는데 도움을 줄 것으로 예상한다. 또한, 인허가 도서 제출과 업무 처리를 BIM 클라우드 서비스 내에서 세움터와 같은 행정관리시스템과 연동 하여 수행함으로써 효율적인 인허가 관련 업무처리를 지원할 것으로 판단된다.

Figure 8은 앞의 과정과 동일하게 기존 실시설계 프로세스에 $\mathrm{BIM}$ 클라우드 서비스를 적용하여 새롭게 구성한 프로세스이다. 앞선 단계와 달리 실시설계 단계에서 지원 가능한 상용 BIM 클 라우드 서비스는 많지 않았다. 하지만 본 연구에서 제안하는 프 로세스에서는 설계 내역서와 시방서를 추가할 수 있는 단계를 추 가함으로써 따로 문서를 관리했던 불편함을 해결하고자 하였다.

\section{BIM 클라우드 서비스 구축을 위한 기능 제안}

Figure 9는 상용 BIM 클라우드 서비스 기능 분석과 BIM 클라 우드 서비스 기능 수요조사, 프로세스 분석 결과를 바탕으로,
설계 단계의 BIM 클라우드 서비스 구현을 위해 필요한 기능을 정리한 것이다. 기존 상용 BIM 클라우드 서비스에서 제공하는 프로젝트 관리, BIM 모델 관리, 뷰어(Viewer) 외에 전문가 조사 등을 통해 도출된 문서관리, BIM 수행 지원, 별도 서비스 모듈 등을 포함하고 있으며, 세부 내용은 다음과 같다.

- 프로젝트 관리: BIM 클라우드 서비스로 업무를 수행함에 앞서 프로젝트를 생성하고, 그에 따른 요구사항 및 사용 자를 관리하는 기능이다. 서비스 내에서 프로젝트를 생성 /수정/삭제할 수 있고 변경사항에 대한 이력을 관리할 수 있도록 한다.

- BIM 모델 관리: 업무수행에 필요한 BIM 모델 등록 및 BIM 작업을 관리하는 기능으로, 다양한 BIM 도구를 활용하는 국내 현실을 고려하여, 개방형 BIM 데이터(IFC 2×3 기준) 및 파일 단위의 BIM 저작도구 원본 파일을 모두 지원하도 록 제안하였다. 모델의 이력 관리, 사용자별 모델의 접근 권한, BIM 수행 계획 수립 및 작업 관리를 할 수 있는 기능 이 이에 포함된다.

- 뷰어(Viewer): BIM 모델이 가진 정보나 오류를 확인하고 확인된 내용을 쉽게 공유하여 설계 업무 관리 및 협업을 지원하는 기능이다. 모델 확인을 위한 기능 외에 협업을 위한 마크업, 단위 업무 관리, 관련 파일 첨부 및 통지 기능을 포함하며, 모델 검토의 활용성을 높이기 위해 간 섭체크, 빌딩 코드 검토, 발주자 요구사항 검토 등을 포함 한다.

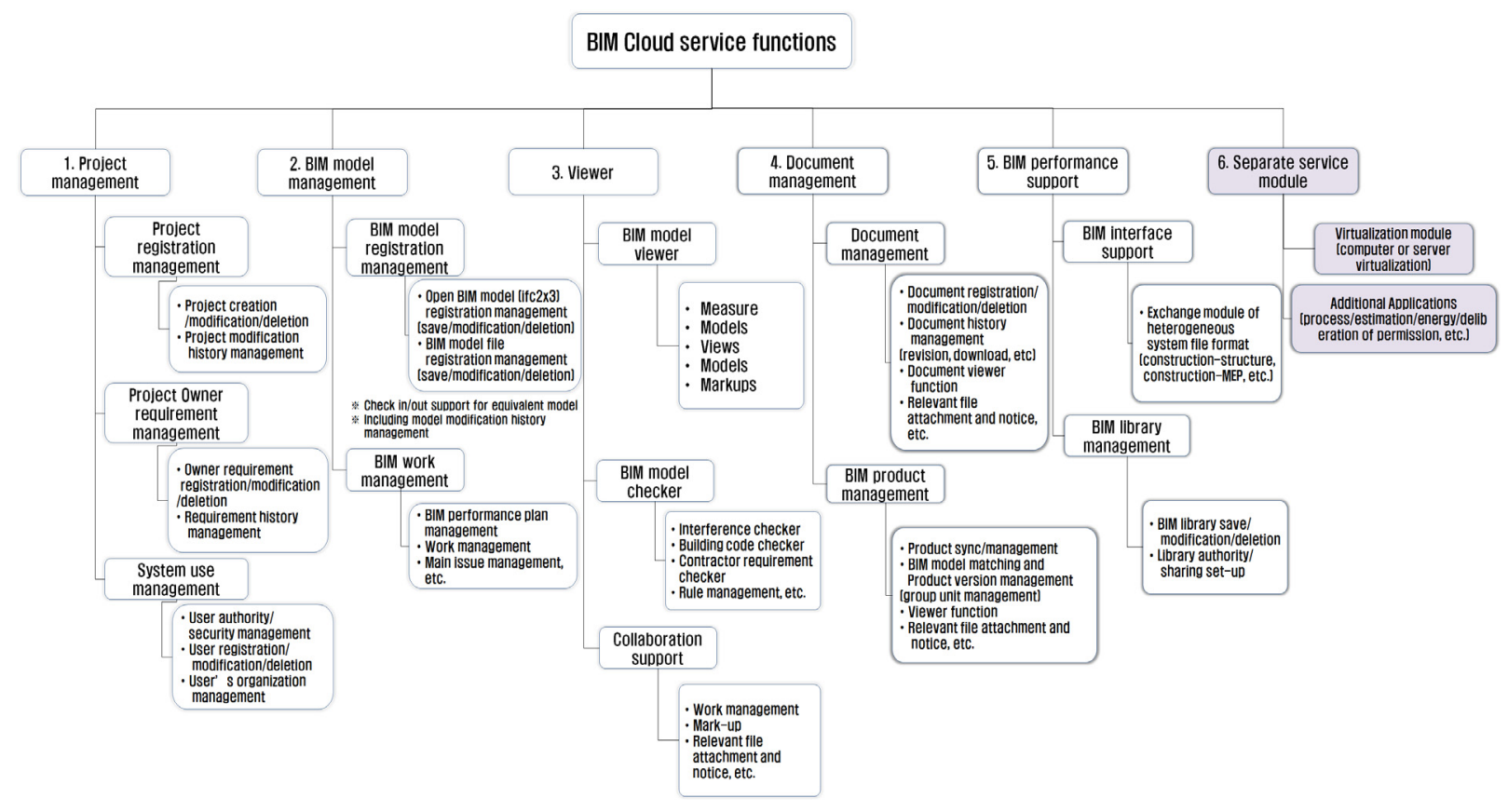

Figure 9 Proposal of BIM Cloud service functions 


\section{Demand survey of cloud based BIM service}

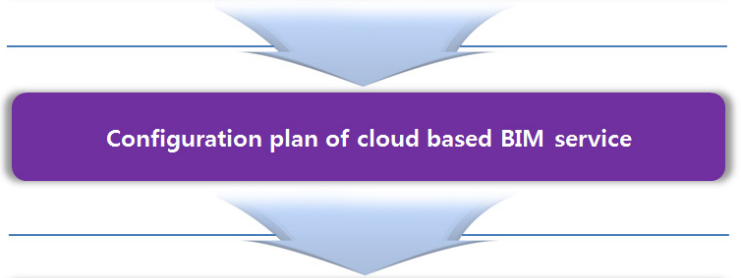

Element technical development of cloud based BIM service

Development of cloud based BIM service

Figure 10. Process of the R\&D Project

- 문서 관리: BIM 업무 수행에 따른 산출물 및 기타 문서를 관리하는 기능으로, 산출물 관리의 경우 해당 BIM 모델 버전과의 연계성을 제공한다. 기본적인 문서 등록/수정/ 삭제 기능과 문서 뷰어(Viewer), 관련 파일 첨부 및 통지 기능, BIM 산출물 버전 관리 기능 등을 포함한다.

- $\mathrm{BIM}$ 수행 지원: BIM 업무 수행에 필요한 이종 시스템 간(건축-구조, 건축-설비 등) 정보 교환을 지원한다. 또 한, $\mathrm{BIM}$ 라이브러리 저장/수정/삭제, 라이브러리 사용자 권한과 공유제한 기능을 통해 BIM 라이브러리 관리를 지 원한다.

- 별도 서비스 모듈: BIM 기반 설계 업무의 관리 및 협업 이외에 특정 업무 지원(공정, 견적, 에너지, 허가 심의 등)을 위한 별도 기능을 제공한다. 이러한 기능은 업무마 다 독립 모듈로 활용이 가능하다. 또한, 인프라 구축비용 절감을 위한 가상화 기능 등을 포함한다.

\section{6. 결론 및 향후 추진 방향}

본 연구에서는 BIM 정보를 생성하는 설계 단계를 대상으로 $\mathrm{BIM}$ 기반의 프로젝트 관리 효율화 및 운영 인프라 비용 절감을 위한 클라우드 컴퓨팅 서비스의 주요 기능을 제안하였다. 서비 스 기능 제안을 위해 먼저 해외 상용 BIM 클라우드 서비스의 제공 기능과 서비스 방식, 연동 소프트웨어를 분석하였으며, 이 를 바탕으로 설계 실무자를 대상으로 한 BIM 업무 환경, BIM 클라우드 서비스의 필요기능, 운영 방안, 제도/정책 지원방안 둥에 대한 설문조사를 실시하였다. 마지막으로 BIM 클라우드 서비스가 지원할 수 있는 설계 프로세스와 업무 단계를 도출하 기 위해 설계 프로세스를 분석하였으며, 이들을 통해 BIM 클라
우드 서비스의 프로젝트 관리, BIM 모델 관리, 뷰어(Viewer), 문 서 관리, BIM 수행 지원, 별도 서비스 모듈과 관련된 기능을 제안 하였다. 이러한 본 연구 결과물은 BIM 클라우드 서비스 구현을 위한 기초자료로 활용될 수 있다고 판단된다.

그리고 본 연구에서 제안한 BIM 클라우드 서비스 기능은 설 계단계를 연구범위로 하고 있다. 하지만 BIM 정보는 시공, 유지 관리단계를 전 생애주기에 걸쳐 활용될 수 있으므로 향후 시공 및 유지관리 단계를 포함하는 BIM 클라우드 서비스 기능에 대한 연구가 필요할 것으로 보인다.

본 연구는 현재 수행 중인 국가 R\&D 과제의 일부이며, 제안 된 기능은 전문가 검증을 통해 보완한 후, 서비스 제공 시스템으 로 개발될 예정이며, 향후 논문 등을 통해 해당 결과를 발표할 예정이다(Figure 10).

\section{감사의 글}

본 연구는 국토교통부 첨단도시개발 및 도시건축연구개발 사 업의 연구비 지원(과제번호: 12-첨단도시-D13, 13-도시건축-C3) 에 의해 수행되었음.

\section{References}

Amarnath, C., Sawhney, A., Maheswari, J. (2011), “Cloud Computing to Enhance Collaboration, Coordination and Communication in The Construction Industry", Information and Communication Technologies (WICT), 2011 World Congress on, pp.1235-1240.

Chuang, T., Lee, B., Wu, I. (2011), "Applying Cloud Computing Technology to BIM Visualization and Manipulation”, 28th International Symposium on Automation and Robotics in Construction.

Hannele, K., Reijo, M., Tarja, M., Sami, P., Jenni, K., Teija, R. (2012), "Expanding Uses of Building Information Modeling in Life-cycle Construction Projects", A Journal of Prevention, Assessment and Rehabilitation, 41:pp. 114-119.

KIRA, Korea Institute of Registered Architects, 〈http://www. kira.or.kr/>

Kalay, Y. E. (2004), “Architecture's New Media: Principles, Theories, and Methods of Computer-aided Design", MIT Press.

Lee, J-H, Park, J-J, Choi, H-A, Jun, H-J (2007), “A Study of Integrated Building Design Process cases based on 
BIM Focusing on Architectural Design Firms”, A Journal of the Architecture Institute of Korea, 27(1):pp.45-48.

Mell, P., Grance, T. (2009), "The NIST Definition of Cloud Computing", National Institute of Standards and Technology, 53(6):p.50.

Seo, C-S, Kim, J-H, Kim, J-J (2010), "A Study on BIM-based Design Work Process Focusing on The Information for Design Management", A Journal of the Korean Institute of Construction Engineering and Management, pp. 133-134.

Won, J-S, Lee, J-J, Lee, G (2008), “A Case Study On BIM Collaboration and Information Management Methods", A Journal of the Architecture Institute of Korea, 24(8): pp. 25-32.
Wu, W., Issa, R. (2012), "Leveraging Cloud-BIM for LEED Automation", A Journal of Information Technology in Construction, pp.367-384.

Yoon, S-W (2013), “A Cloud Computing Adoption Strategy to Improving BIM Utilization in Construction Site", A Journal of the Korean Institute of Construction Engineering and Management, pp.71-72.

BIM 360 Glue. (www.autodesk.com/products/bim-360-glue)

SkyBIM. (www.skybim.com)

BIM 9. (www.bim9.com)

G Team. (www.thegteam.com)

Tekla BIMSight. (www.teklabimsight.com)

Graphisoft BIMcloud. (www.graphisoft.com/bimcloud) 